\title{
A High-throughput Synthetic Platform Enables the Discovery of Proteomimetic Cell Penetrating Peptides and Bioportides
}

\author{
Sarah Jones ${ }^{1}$, Shaimaa Osman ${ }^{1,2}$, John Howl ${ }^{1}$ \\ ${ }^{1}$ Research Institute in Healthcare Science, University of Wolverhampton, Wulfruna Street, \\ Wolverhampton WV1 1LY, UK. \\ ${ }^{2}$ Peptide Chemistry Department, National Research Centre, Dokki 12622, Cairo, Egypt.
}

Key words: bioportide; cell penetrating peptide; microwave-enhanced peptide synthesis; confocal microscopy

Correspondence: Professor John Howl, Research Institute in Healthcare Science, University of Wolverhampton, Wulfruna Street, Wolverhampton WV1 1LY, UK.

Email: J.Howl@wlv.ac.uk

Phone: +44 (0)1902 321131 
Abstract: Collectively, cell penetrating peptide (CPP) vectors and intrinsically active bioportides possess tremendous potential for drug delivery applications and the discrete modulation of intracellular targets including the sites of protein-protein interactions (PPIs). Such sequences are usually relatively short ( $<25 \mathrm{AA})$, polycationic in nature and able to access the various intracellular compartments of eukaryotic cells without detrimental influences upon cellular biology. The high-throughput platform for bioportide discovery described herein exploits the discovery that many human proteins are an abundant source of potential CPP sequences which are reliably predicted using QSAR algorithms or other methods. Subsequently, microwave-enhanced solid phase peptides synthesis provides a highthroughput source of novel proteomimetic CPPs for screening purposes. By focussing upon cationic helical domains, often located within the molecular interfaces that facilitate PPIs, bioportides which act by a dominant-negative mechanism at such sites can be reliably identified within small number libraries of CPPs. Protocols that employ fluorescent peptides, routinely prepared by N-terminal acylation with carboxytetramethylrhodamine (TAMRA), further enable both the quantification of cellular uptake kinetics and the identification of specific site(s) of intracellular accretion. Chemical modifications of linear peptides, including strategies to promote and stabilise helicity, are compatible with the synthesis of second-generation bioportides with improved drug-like properties to further exploit the inherent selectivity of biologics. 


\section{INTRODUCTION}

The eukaryotic plasma membrane represents a significant obstacle for the development of both drugs and biological research tools that require access to intracellular target sites to influence cellular biology. Cell penetrating peptides (CPPs) are a versatile technology that can negate the pharmacokinetic challenges of lipid barriers to afford the efficient delivery of bioactive cargoes (Mae and Langel 2006, Milletti 2012). More recently, a novel genre of CPP, distinct from conventionally inert vectors, has been described (Howl and Jones 2008, Howl et al. 2012) which combines the dual properties of cellular penetration and biological activity. Termed bioportides (Howl and Jones 2008, Howl et al. 2012), these proteomimetic CPPs often derive from cationic helical domains of key signalling proteins and commonly act as biological modulators of protein-protein interactions (PPIs; Howl and Jones 2008, Howl et al. 2012, Howl et al. 2015, Lukanowska et al. 2013).

Collectively, CPP and bioportide technologies possess tremendous potential to modulate intracellular protein function and so expand the known repertoire of drug targets. An overwhelming majority of recently developed CPPs are relatively short (12-25 AA) sequences in which both lysine and, perhaps more commonly, arginine contribute to a net positive charge. Some of these, including the common delivery vectors Tat (GRKKRRQRRRPPQ; Vivés et al. 1997) and Penetratin (RQIKIWFQNRRMKWKK;

Derossi et al. 1994), derive from known helical domains of transcription factors which facilitate membrane translocation. Other CPP sequences, including the Transportans (Soomets et al. 2000) can be successfully modelled as an amphipathic helix. Polyargininecontaining CPP sequences have also been identified as cryptic fragments of the primary sequences of other structurally-diverse human proteins (Futaki et al. 2001). Thus, it is tempting to speculate that one or multiple polycationic sequences may enable functionally- 
diverse supercharged proteins (Cronican et al. 2011) to traverse biological membranes and so fulfil their biological role(s).

Robust methodologies, employing quantitative structure -activity relationship (QSAR) models (Hällbrink et al. 2005), to accurately predict CPPs within vertebrate proteins are described herein. Protocols for the high-throughput synthesis of polycationic peptides using microwave-enhanced solid-phase methodologies are also reported. As developed to confirm and quantify effective cellular penetration (Howl et al. 2012, Jones et al. 2010, Jones et al. 2016), we also describe both qualitative and quantitative methodologies that permit an assessment of translocation efficacies and determination of the intracellular sites of accretion of both CPPS and bioportides. Finally, we suggest a variety of structural modifications, compatible with microwave-enhanced solid phase synthesis, which may improve both the pharmacokinetic and pharmacodynamic properties of bioportides. Collectively, these sequential methodologies permit the positive identification of bioportides that possess some of the desirable properties associated with small molecular weight drugs whilst retaining the exquisite selectivity and potency of macromolecular biologics (Craik et al. 2013).

\section{Experimental}

\section{Selection of Cryptic Peptide Sequences}

The initial step towards the synthesis of linear proteomimetic CPPs is to identify cationic stretches within the primary sequence of entire proteins or those with a more restricted distribution within protein domains with a known regulatory function. As first described by Futaki and co-workers (2001), many arginine-rich sequences, 12-28 AA in length and identified within both RNA- and DNA-binding proteins, proved to be efficient CPPs. By 
analogy with the Tat peptide (Vivés et al. 1997), these observations indicate the relative ease by which it is possible to identify new CPP sequences and suggest that polybasic proteins might utilise common internalisation mechanisms to achieve a cellular response (Cronican et al. 2011),

QSAR analyses provide a more scientifically rigorous approach to the identification of novel proteomimetic CPPs. The training of a QSAR prediction algorithm with known CPP sequences supports the comparison of the bulk properties of amino acids within primary sequences. Two of four Q variable scores are particularly important descriptors of CPPs and can be used to reliably predict others that are cryptic fragments of whole proteins. For this purpose, we have often utilised the platform developed by Langel's team in Stockholm (Hällbrink et al. 2005) that in our experience is particularly reliable for the prediction of new CPPs that are $\geq 12$ amino acids in length (Fig. 1A). Publicly-accessible sites that provide a similar readout using mathematical prediction are more recently available and include CellPPD: Designing of Cell Penetrating Peptides (www.imtech.res.in/raghava/cellppd/; Gautam et al. 2015)). It would be particularly informative to compare the outputs from different predictive platforms with the anticipation of identifying some consensus.

It is common that QSAR analyses (Hällbrink et al. 2005) identify many overlapping CPPs within vertebrate proteins. For example, human Cytochrome ${ }_{\mathrm{c}}$ was predicted to contain 25 polycationic CPPs (Jones et al. 2010). Within the primary sequence of larger proteins such as the Leucine Rich Repeat Kinase 2 the total number of predicted CPPs exceeds 2,500. Moreover, we commonly observed that QSAR prediction illuminated CPPs within cationic helices including those that reside at the sites of protein-protein interactions. A striking example was provided by our studies with Cytochrome ${ }_{\mathrm{c}}$ in which all predicted CPPs derived from spatially contiguous helical domains at the $\mathrm{N}$ - and $\mathrm{C}$ - termini of the protein (Howl et al. 2010). Thus, in our search for rhegnylogically-organised bioportides (Howl and Jones 2008, 
Howl et al. 2012, Howl et al. 2015, Lukanowska et al. 2013), we have focussed efforts upon those predicted CPPs which derive from well-defined protein structures, particularly $\alpha$ helices.

\section{Microwave Enhanced Solid Phase Peptide Synthesis}

It is perfectly feasible to synthesise CPPs and bioportides at room temperature in simple glass reaction vessels employing standard protocols for activation and deprotection from 9Fluorenylmethyloxycarbonyl (Fmoc)-protected AAs (Chan and White, 1999). We now utilise such methods mostly for the amino-terminal acylation of peptides on resin with fluorophores and instead prefer to employ microwave-enhanced peptide chemistry. Synthesis at higher temperatures, 75 or $90^{\circ} \mathrm{C}$, reduces cycle times and often improves both the purity and yield of the desired product. Detailed protocols for the semi-automated synthesis of peptides with a Discover SPS Microwave Peptide Synthesizer are reported elsewhere (Howl and Jones 2015a). Using this system, O-(1H-6-Chlorobenzotriazole-1-yl)-1,1,3,3tetramethyluronium hexafluorophosphate (HCTU) is a reliable condensation reagent and most coupling reactions were performed at $75^{\circ} \mathrm{C}$ for 10 mins.

Higher throughput using a CEM Liberty Blue Synthesizer equipped with UV analyser is now our method of choice for the routine synthesis of polycationic CPPs and bioportides in Dimethylformamide (DMF). To negate a negatively charged carboxyl terminal, which could be detrimental to cellular penetrations, and to improve stability against proteases, we commonly synthesize CPPs and bioportides on Rink Amide 4-Methylbenzhydrylaamine (MBHA) cross-linked polystyrene resins (Novabiochem) to generate peptide amides. Whilst compatible with HCTU chemistry, when using this synthetic platform we routinely employ a coupling methodology developed by CEM to facilitate synthesis at $90^{\circ} \mathrm{C}$ with enhanced 
coupling efficiency and reduced side reactions. For this purpose, N,N'-

Diisopropylcarbodiimide (DIC) is used as the condensation reagent with the additive Ethyl 2cyano-2-(hydroxyimino)acetate (Oxyma; Subirs-Funosas et al. 2009) plus a lower concentration of N,N-Diisopropylyethylamine (DIPEA). Syntheses on a 0.1 mmole scale are performed using a 5-fold molar excess of AA/DIC/Oyxma with 0.1 molar equivalent of DIPEA in a final volume of $4 \mathrm{ml}$. Microwave power is routinely applied in three steps to rapidly heat reagents in the $30 \mathrm{ml}$ reaction vessel and subsequently more accurately maintain the final temperature for the desired period. For example, a standard coupling of most AAs is achieved (power/maximum temperature/time) by $100 \mathrm{~W} / 80^{\circ} \mathrm{C} / 20 \mathrm{~s}, 55 \mathrm{~W} / 86^{\circ} \mathrm{C} 10 \mathrm{~s}, 20 \mathrm{~W}$, $90^{\circ} \mathrm{C} / 120 \mathrm{~s}$ to minimise temperature fluctuations around the holding temperature of $90^{\circ} \mathrm{C}$. Special coupling cycles are used for Arg, double coupling $30 \mathrm{~W} / 75^{\circ} \mathrm{C} / 300 \mathrm{~s}$, and Cys/His, single coupling $30 \mathrm{~W} / 50^{\circ} \mathrm{C} / 600 \mathrm{~s}$. These protocols reduce $\delta$-lactam formation of arginine and racemisation of Cys/His respectively. A standard deprotection cycle with 20\% (v/v) Piperidine in DMF is reduced to $60 \mathrm{~s}$ at $90^{\circ} \mathrm{C}$ and is routinely monitored by determining the UV absorption at $301 \mathrm{~nm}$ of Dibenzofulvene-piperidine adducts (Fig. 2).

Amino-terminal acylation of CPPs and bioportides is a convenient route to the production of fluorescent peptides for applications such as confocal microscopy (Fig. 1B). We favour the single isomer 6-Carboxytetramethylrhodamine for applications with eukaryotic cell systems as this chromophore provides excellent photo-stability and pHinsensitive fluorescence (Jones et al. 2016). All peptides described herein were purified to apparent homogeneity by reverse phase HPLC and analysed by mass spectroscopy (Fig. 1C) to confirm their mass (Howl et al. 2012, Jones et al. 2016). 


\section{Live Cell Confocal Microscopy}

To avoid the potential for fixation artefacts that could promote a redistribution of fluorescent peptides, we routinely utilise living cell monolayers to assess the intracellular uptake of TAMRA-conjugated CPPs and bioportides (Howl et al. 2012, Jones et al. 2016). Cells are cultured in $35 \mathrm{~mm}$ glass base dishes and incubated with fluorescent peptides whilst maintaining standard culture conditions of $37^{\circ} \mathrm{C}$ and a humidified atmosphere of $5 \% \mathrm{CO}_{2}$. As a rule, a final assay concentration of $5 \mu \mathrm{M}$ peptide is used in initial experiments to provide optimal signal intensity whilst avoiding possible non-specific membrane perturbations associated with high concentrations of CPP (Howl and Jones 2015a). Immediately prior to observation, cells are washed gently with phenol red free medium (8x) and subsequently analysed with a Carl Zeiss LSM510Meta confocal microscope equipped with a live cell imaging chamber. Other fluorescent dyes providing a single carboxylic acid, including fluorescein, are also readily conjugated to CPPs and bioportides using conventional peptide chemistry. A variety of fluorescent markers can be employed (Jones et a. 2010, Jones ert al, 2016) to confirm the intracellular distribution of CPPs and bioportides in living cells (Fig. 1D).

\section{Quantitative Assessment of Cellular Internalisation}

Fluorescent CPPs and bioportides are convenient probes with which to quantify cellular internalisation (Fig. 1D). In many of our studies (Jones et al. 2010, Jones et al. 2016), we have employed U373MG astrocytoma cells routinely maintained in a humidified atmosphere of $5 \% \mathrm{CO}_{2}$ at $37^{\circ} \mathrm{C}$ in DMEM supplemented with L-glutamine $(0.1 \mathrm{mg} / \mathrm{ml}), 10 \%$ (wt/vol) fetal bovine serum (FBS), penicillin $(100 \mathrm{U} / \mathrm{ml})$ and streptomycin $(100 \mu \mathrm{g} / \mathrm{ml})$. Unlike our 
confocal analyses of cellular penetration, this method permits the incorporation of a trypsinisation step so as to remove non-internalised cell surface-associated peptide. For this purpose, U373MG cells are transferred to 6-well plates and grown to 80\% confluence. Cells are washed and maintained in phenol red-free DMEM and subsequently treated with TAMRA-conjugated peptides at a final concentration of $5 \mu \mathrm{M}$ for 1 hour in culture conditions as above. Cells were then washed four times, detached with $300 \mu \mathrm{l}$ of $1 \%$ (w/v) trypsin (without phenol red) at $37^{\circ} \mathrm{C}$, collected by centrifugation and lysed in $300 \mu \mathrm{l} 0.1 \mathrm{M}$ $\mathrm{NaOH}$ for two hours on ice. $250 \mu \mathrm{l}$ of each sample cell lysate are transferred to a black 96well plate, and analysed using a ThermoFischer Scientific Fluoroskan Ascent FL flurorescence spectrophotometer ( $\lambda$ Abs $544 \mathrm{~nm} / \lambda \operatorname{Em} 590 \mathrm{~nm}$ ), (Fig. 1D). 


\section{Results and Discussion}

Many bioportides derive from known cationic domains of signalling proteins and the amphipathic helix is a common structural motif that may be essential for both cellular entry and bioactivities. Thus, the focus of our efforts to develop bioportides which mimic cationic helices within human proteins affords advantages that are both pharmacokinetic and pharmacodynamic in nature. Key to this strategy is the knowledge that cationic residues, predominantly Arg, play a common role in the enabling of CPPs to enter cells and the subsequent modulation of intracellular protein function (Lukanowska et al. (2013); Howl and Jones, 2015b). After binding to the surface of cells, CPPs and bioportides access the cellular interior by a variety of mechanisms that may include a combination of both direct translocation and various energy-dependent endocytotic processes (Langel, 2007). Following internalisation, possibly in a helical conformation, bioportides commonly exhibit site-specific accretion that may enhance or reflect their capacity to modulate the activity of proteins preferentially located within defined intracellular loci (Futaki et al. 2001, Lukanowska et al. 2013). Polycationic $\alpha$-helices are a quantitatively dominant secondary structure within the extended surfaces that constitute the protein-protein interfaces (PPIs) between therapeutically-relevant proteins (Jochim and Arora, 2009). Moreover, within PPIs Arg is commonly enriched (Crowley and Golovin, 2005). Since PPIs are ubiquitous modulators of all major signalling pathways that often utilise common promiscuous domains (Pawson and Nash, 2000) it is not surprising that aberrant PPI function is a causative factor of many human disease states (Vidal et al. 2011). Hence, there is tremendous scope to develop proteomimetic bioportides and the platform described herein is fully compatible with synthesis of larger libraries of potential bioportides that could accelerate the drug discovery process (Derda 2015). 
Many bioportides most likely mimic cationic helices within PPI interfaces to achieve their biological functions through a predominant dominant-negative mechanism (Kiosses et al. 2002, Howl and Jones 2015b). For example, Harada and co-workers (2010) employed the cell permeable undecaarginine (Arg11) to deliver a peptidomimetic fragment of the zinc finger 224 (ZNF224) interacting domain of human DEP containing 1 protein (DEPDC1611628). This sychnologic bioportide (Howl et al. 2008, Lukanowska et al. 2013, Howl and Jones 2015b) aptly named DEPDC1-ZNF224, inhibited the interaction of DEPDC1 and ZNF244 to trigger transcriptional activation of the A20 zinc finger protein leading to growth repression of bladder cancer cells (Harada et al. 2010),

It is apparent that folded sub-domains enable proteins to interact in a temporal and spatial fashion with their cognate binding partners (Ghoorah et al. 2015). The stabilisation of peptides into a defined $\alpha$-helical conformation can confer distinct pharmacodynamic and pharmacokinetic advantages; so many strategies have been developed to achieve this synthetic goal (Fig. 3). For example, $\alpha$, $\alpha$-dialkylamino acids such as $\alpha$-Aminoisobutyric acid (Aib) can be incorporated into peptides to increase the propensity for helix formation (Howl and Jones 2015b). We commonly substitute Aib for Ala when seeking to employ this simple modification. Disulphide bonds, lactam- and metal-mediated bridges, plus a variety of other covalent bonds, are also commonly employed to introduce relatively flexible or rigid crosslinks that stabilise a helical peptide conformation (Henchey et al. 2008). The engineering of bioportides with more drug-like properties may be one of the key challenges for many clinical applications. As indicated (Fig. 3), complementary strategies may be utilised to improve proteolytic stability, membrane translocation and site-directed intracellular target-site affinity. For example, Aileron Therapeutics has recently reported (Chang et al. 2013) the development of a stapled $\alpha$-helical peptide, ATSP-7041, that is a dual inhibitor of the Murine double minute (MDM) family members MDM2 and MDMX. Of a 
more unconventional nature (Fig. 3), the design of bivalent analogues of both linear and helical bioportides could display enhanced affinity for their intracellular therapeutic target (Schiller, 2010).

\section{Conclusions}

The presented high-throughput methodologies for the generation of proteomimetic CPPs and bioportides provide a unique platform which traverses the scientific disciplines of chemistry and biology - from identification and synthesis, to the determination of intracellular fate and, finally, the discrete modulation of intracellular processes. Whilst peptide therapeutics have been somewhat neglected by the pharmaceutical industry, largely owing to their susceptibility to premature proteolysis in vivo, a wealth of stabilisation strategies are now emerging which render peptides more pharmacokinetically and yet more pharmacodynamically favourable. Such strategies, applicable to both CPPS and bioportides, include modifications which are compatible with the formation and stabilisation of cationic $\alpha$-helices, our favoured locus for the therapeutic targeting of PPIs. We trust that our description of this discovery platform will encourage others to utilise this emerging technology and to address the development of second-generation bioportides that are chemically modified and stabilised linear peptides. Such developments will also exploit the unparalleled target specificity and affinity afforded by larger macromolecules (Craik et al. 2013) to offer significant promise for the next generation of intracellular peptide therapeutics.

Acknowledgements: The authors gratefully acknowledge the support provided by Chris Mason and CEM towards the development and maintenance of a microwave-enhanced 
peptide synthesis facility. Shaimaa Osman was in receipt of Newton-Mosharafa Fellowship from 2015-17.

Conflict of interest: The authors declare no conflicts of interest.

Ethical approval: This article does not present and studies performed with human participants or animal. 


\section{FIGURE LEGENDS}

Fig. 1. A high-throughput synthetic platform for the discovery of CPPs and bioportides. A) QSAR analyses can reliably identify CPP sequences within many human proteins or selected domains (Hällbrink et al. 2005, Howl et al. 2012). The algorithm developed in Stockholm provides a numerical indication of CPP probability that rises from possible (1), to probable (2) and highly probable (3). This figure indicates that nosangiotide $(H$ RKKTFKEVANAVKISA- $\mathrm{NH}_{2}$ ), a potent anti-angiogenic bioportide (Howl et al. 2012) was predicted to be a "highly probable" CPP.

B) Microwave-enhanced peptide synthesis provides a convenient and reliable route towards the synthesis of de novo CPPs and bioportides. The average time required for the synthesis of a polycationic tetradecapeptide, such as $\mathrm{H}$-INLKKLAKL(Aib)KKIS- $\mathrm{NH}_{2}$, a derivative of the mitochondriotoxic bioportide mitoparan (Jones et al. 2008; Fig. 2B (ii)), is reduced from several days using manual synthesis to just two hours once the CEM instrument is loaded with reagents. A fraction, usually $\sim 0.025$ mmole, of the synthesised peptides undergo $\mathrm{N}$ terminal acylation with TAMRA to provide fluorescent probes for both quantitative and qualitative cellular uptake analysis.

C) Since we tend to sacrifice yield for purity, the HPLC purification of peptides is now a rate-limiting step in this high-throughput scheme. We routinely use semi-preparative scale methodologies with $4.5-5.5 \mathrm{mlmin}^{-1}$ flow rates employing a $250 \mathrm{~mm}$ length x $10 \mathrm{~mm}$ diameter $\mathrm{C}_{18}$ reverse phase column optimised for the separation of peptides in the range of 10 -20 AA. The requirements of multiple runs, usually 5or 6 , to purify the entire output from a 0.1 mmole synthesis at least allows for occasional mistakes to be made.

D) Both quantitative and qualitative methods are routinely employed to establish cellular uptake of TAMRA-labelled bioportides. Fluorescence spectroscopy permits the 
quantification of cellular penetration. An additional trypsinisation step is essential to remove any cell surface-associated peptide. To complement these quantitative data, real-time live confocal cell imaging analyses are used to determine the precise intracellular distribution of TAMRA-labelled bioportides. Cellular fixation is ill-advised owing to artefactual redistribution of the bioportide. Fluorescent labelling of organelles or proteins further enables quantitative co-localisation analysis which measures the degree of bioportide accretion within subcellular structures (Jones et al. 2010). The confocal image depicts TAMRA-Cyt $c^{77-101}$ accumulation within the endoplasmic reticulum (Jones et al. 2010) labelled with ER Tracker Green FM (Molecular Probes).

Fig 2. Semi-quantitative analysis of Fmoc removal is a convenient quality control assessment of automated microwave-enhanced peptide synthesis.

A) Piperidine is commonly utilised to afford the removal of the $\mathrm{N}-\alpha$-Fmoc groups to liberate a free amine and the Dibenzofulvene-piperidine adduct (DBF-pip). The absorbance of DBFpip at $301 \mathrm{~nm}$ is distinct from that of other reagents and so provides a semi-quantitative assessment of both Fmoc-removal and coupling efficiency.

Bi) The successful synthesis of the hexadecapeptide $H$-RKFPSKKHMQRHIRSH-NH$H_{2}$, which was subsequently purified in high yield. This is a cationic sequence located within the Ovo transcription factor of the planarian Schmidtea mediterrane (Ovo ${ }^{236-249}$; Mével-Ninio et al. 1991) with an Arg-Lys N-terminal chimeric extension.

Bii) The attempted synthesis of the tetradecapeptide $\mathrm{H}$-SIKK(Aib)LKALKKLNI- $\mathrm{NH}_{2}$, where Aib $=\alpha$-aminoisobutyric acid, a CPP sequence with potential antimicrobial activities. This synthetic process clearly failed and attempts to purify the required sequence proved unsuccessful. Double coupling the final three amino acids solved this synthetic problem to 
enable purification of the desired product in high yield. As shown in both bottom panels, it is noteworthy that we often observe that a reduced amount of Fmoc is liberated by the first deprotection of the resin. We interpret this observation as indicative that not every linker attached to the solid phase resin is chemically protected.

Fig. 3. Strategies for the synthesis of stabilised bioportides. In addition to the chemical variation of peptide termini and the substitution of unnatural or D amino acids (Howl and Jones 2015b), rational synthetic modifications could convert promising functional leads into more stable homologues.

A) Detailed protocols for the introduction of a chemical staple using olefin metathesis are available (Kim et al. 2011) though a variety of complementary strategies can also be employed to stabilise peptides in a helical formation (Henchey at al. 2008).

B) Cyclisation of linear peptides in monomeric or dimeric form will almost certainly improve oral bioavailability (Wang and Craik, 2016. Furthermore, bivalent and cyclic bioportides are likely to possess higher potencies than their monomeric precursors (Keissling et al. 2000, Schiller 2010, Kim et al. 2011, Wang and Craik, 2016).

C) The dimerisation of stabilised helical monomers could combine the intrinsic stability of cyclic peptides with the pharmacodynamic advantages resulting from both enhanced helicity and bivalency. The synthesis of cyclic structurally-constrained peptides will not be routine, though the preparation of double-stapled helical peptides is compatible with Fmoc-based peptide chemistry (Walensky and Bird, 2014), 


\section{References}

Chan W, White P. (Eds.) Fmoc Solid Phase Peptide Synthesis, Oxford University Press, 1999.

Chang YS1, Graves B, Guerlavais V, Tovar C, Packman K, To KH, Olson KA, Kesavan K, Gangurde P, Mukherjee A, Baker T, Darlak K, Elkin C, Filipovic Z, Qureshi FZ, Cai H, Berry P, Feyfant E, Shi XE, Horstick J, Annis DA, Manning AM, Fotouhi N, Nash H, Vassilev LT, Sawyer TK (2013) A potent dual inhibitor of MDM2 and MDMX for p53dependent cancer therapy. Proc. Nat. Acad. Sci. USA 110:E3445-E3454.

Craik DJ, Fairlie DP, Liras S, Price D (2013) The future of peptide-based drugs. Chem. Biol. Drug Des. 81:136-147.

Cronican J, Beier KT, Davis TN, Tseng JC, Li W, Thompson DB, Shih AF, May EM, Cepko CL, Kung AL, Zhou Q, Liu DR (2011) A class of human proteins that deliver functional proteins into mammalian cells in vitro and in vivo. Chem. \& Biol. 18: 833-838.

Crowley PB, Golovin A (2005) Cation- $\pi$ interactions in protein-protein interfaces. Proteins 59:231-239.

Derda, R (Ed) Peptide libraries: Methods and protocols. Springer, New York, 2015. 
Derossi D, Joliot AH, Chassaing G, Prochiantz A (1994) The third helix of the Antennapedia homeodomain translocates through biological membranes. J. Biol. Chem. 269:10444-10450.

Futaki S, Suzuki T, Ohashi W, Yagami T, Tanaka S, Ueda K, Sugiura Y (2001) Arginine-rich peptides. An abundant source of membrane-permeable peptides having potential as carriers for intracellular protein delivery. J. Biol. Chem. 276:5836-5840.

Gautam A, Chaudhary K, Kumar R, Raghava GPS (2015) Computer-aided virtual screening and designing of cell-penetrating peptides. Meth. Mol. Biol. 1324:59-69.

Ghoorah AW, Devignes M-D, Aborzi SZ, Smaïl-Tabbone M, Ritchie DW (2015) A structure-based classification and analysis of protein domain family binding sites and their interactions. Biology 4:327-343.

Hällbrink M, Kilk K, Elmquist A, Lundberg P, Lindgren M, Jiang Y, Pooga M, Soomets U, Langel Ü (2005) Prediction of Cell-Penetrating Peptides. Int. J. Pept. Res. Ther. 11:249-259.

Harada Y, Kanehira M, Fujisawa Y, Takata R, Shuin T, Miki T, Fujioka T, Nakamura Y, Katagiri T (2010) Cell-permeable peptide DEPDC1-ZNF224 interferes with transcriptional repression and oncogenicity in bladder cancer cells. Cancer Res. 70:5829-5839.

Henchey LK, Jochim AL, Arora PS (2008) Contemporary strategies for the stabilization of peptides in the $\alpha$-helical conformation. Curr. Opin. Chem. Biol. 12:692-697. 
Howl J, Jones S (2008) Proteomimetic Cell Penetrating Peptides. Int. J. Pept. Res. Ther. 14:359-366.

Howl J, Jones S (2015a) Protein mimicry and the design of bioactive cell-penetrating peptides. Meth. Mol. Biol. 1324:177-190.

Howl J, Jones S (2015b) Insights into the molecular mechanisms of action of bioportides: a strategy to target protein-protein-interactions. Expert Rev. Mol. Med. DOI: 10.1017/erm.2014.24. Vol 17, e1.

Howl J, Matou-Nasri S, West DC, Farquhar M, Slaninová J, Östenson C-G, Zorko M, Östlund P, Kumar S, Langel Ü, McKeating J, Jones S (2012) Bioportide: an emergent concept of bioactive cell-penetrating peptides. Cell. Mol. Life. Sci. 69:2951-2966.

Jochim AL, Arora PS (2009) Assessment of helical interfaces in protein-protein interactions. Mol. Biosyst. 5:924-926.

Jones S, Holm T, Mäger I, Langel Ü. Howl J (2010) Characterisation of bioactive cell penetrating peptides from cytochrome c: protein mimicry and the development of a novel apoptogenic agent. Chem. \& Biol. 17:735-744.

Jones S, Martel C, Belzacq-Casagrande A, Brenner C, Howl J. (2008) Mitoparan and targetselective chimeric analogues: membrane translocation and intracellular redistribution induces mitochondrial apoptosis. Biochim. Biophys. Acta. Mol. Cell. Res. 1783:849-863. 
Jones S, Uusna J, Langel Ü, Howl J (2016) Intracellular target-specific accretion of cell penetrating peptides and bioportides: Ultrastructural and biological correlates. Bioconjugate Chem. 27:121-129.

Keissling LK, Gestwick JS, Strong LE (2000) Synthetic multivalent ligands in the exploration of cell-surface interactions. Curr. Opin. Chem. Biol. 4:696-703.

Kim YW, Grossmann TN, Verdine GL (2011) Synthesis of all-hydrocarbon stapled $\alpha$-helical peptides by ring-closing olefin metathesis. Nat. Protoc. 6:761-771.

Kiosses WB, Hood J, Yang S, Gerritsen ME, Cheresh DA, Alderson N, Schwartz MA (2002) A dominant negative p65 PAK peptide inhibits angiogenesis. Circ. Res. 90:697-702.

Langel, Ü (Ed.) Handbook of cell-penetrating peptides. CRC Press, Boca Raton, 2007.

Lukanowska M, Howl J, Jones S (2013) Bioportides: Bioactive cell-penetrating peptides that modulate cellular dynamics. Biotechnol. J. 8:918-930.

Mae M, Langel Ü (2006) Cell-penetrating peptides as vectors for peptide, protein and oligonucleotide delivery. Curr. Opin. Pharmacol. 6:509-514.

Mével-Ninio M, Terracol R, Kafatos FC (1991) The ovo gene of Drosophila encodes a zinc finger protein required for female germ line development. EMBO J. 10:2259-2266. 
Milletti F (2012) Cell-penetrating peptides: classes, origin, and current landscape. Drug Discov. Today 17:850-860.

Pawson T, Nash P (2000) Protein-protein interactions define specificity in signal transduction. Genes Dev. 14:1027-1047.

Schiller PW (2010) Bi- or multifunctional peptide drugs. Life Sci. 86:598-603.

Soomets U, Lindgren M, Gallet X, Hälbrink M, Elmquist A , Balaspiri L , Zorko M , Pooga M , Brasseur R , Langel U (2000) Deletion analogues of transportan. Biochim. Biophys. Acta $1467: 165-176$.

Subirs-Funosas R, Prohens R, Barbas R, El-Faham A, Albericio F (2009) Oxyma: An efficient additive for peptide synthesis to replace the benzotriazole-based HOBt and HOAt with a lower risk of explosion. Chem. Eur. J. 15:9394-9403.

Vidal M, Cusick ME, Barabási A-L (2011) Interactome networks and human disease. Cell 144:986-998.

Vivès E, Brodin P, Lebleu B (1997) A truncated HIV-1 Tat protein basic domain rapidly translocates through the plasma membrane and accumulates in the cell nucleus. J. Biol. Chem. 272:16010-16017.

Walensky LD, Bird GH (2014) Hydrocarbon-stapled peptides: Principles, practice and progress. J. Med. Chem. 57:6275-6288. 
Wang CR, Craik DJ (2016) Cyclic peptide oral bioavailability: Lessons from the past. Pept. Sci. 106:901-909. 
Fig. 1

A

Sequence selection of candidate bioportides

B

Peptide synthesis

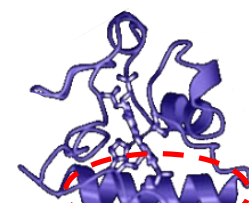

crisu

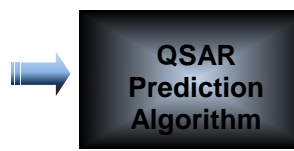

Sequence

CPP Index
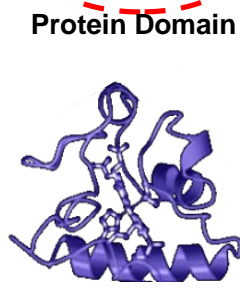

Whole Protein

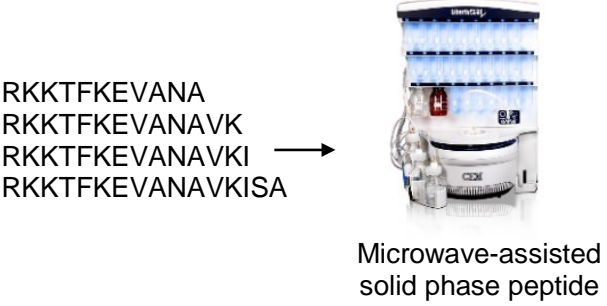

$$
\text { synthesis }
$$

HPLC
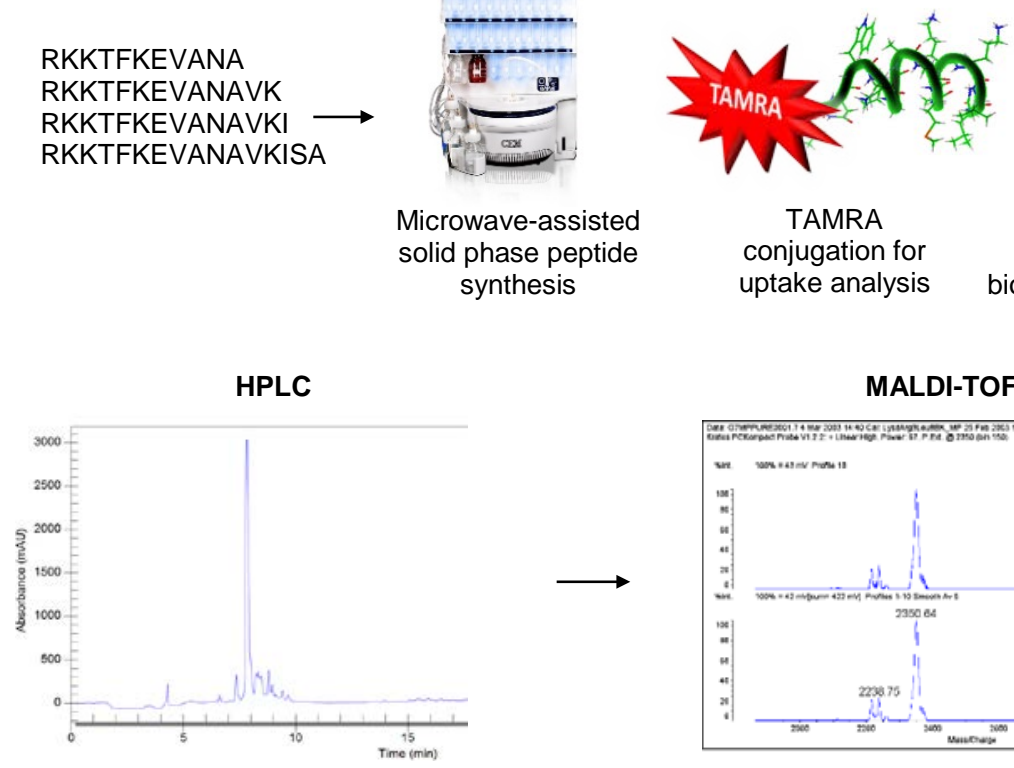

TAMRA conjugation for uptake analysis

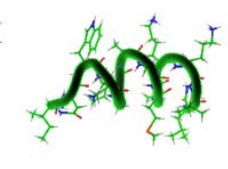

Unconjugated bioportides for biological screening

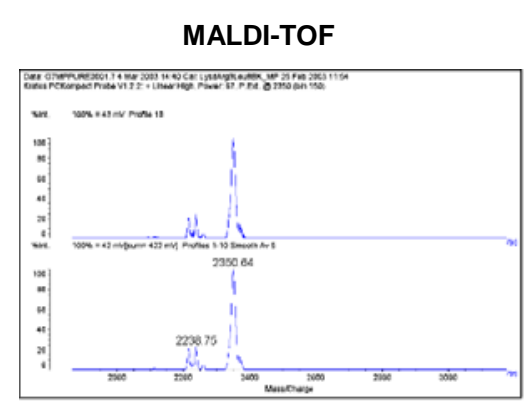

Determination of intracellular distribution

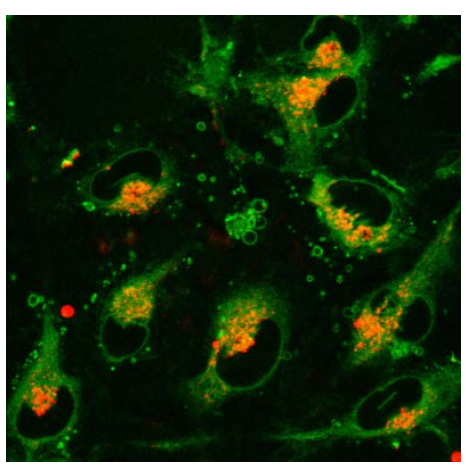

Confocal live cell imaging
Incubate adherent cells with fluorescent labelled CPP

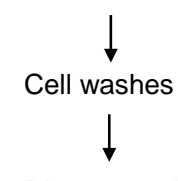

Digest membrane bound CPP with trypsin

Collect cells by gentle centrifugation

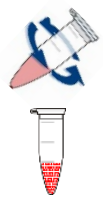

Fluorescence

Lyse the pellet spectroscopy
EVANAVKISASLMG 1
Peptide purification and analysis 
Fig. 2

A
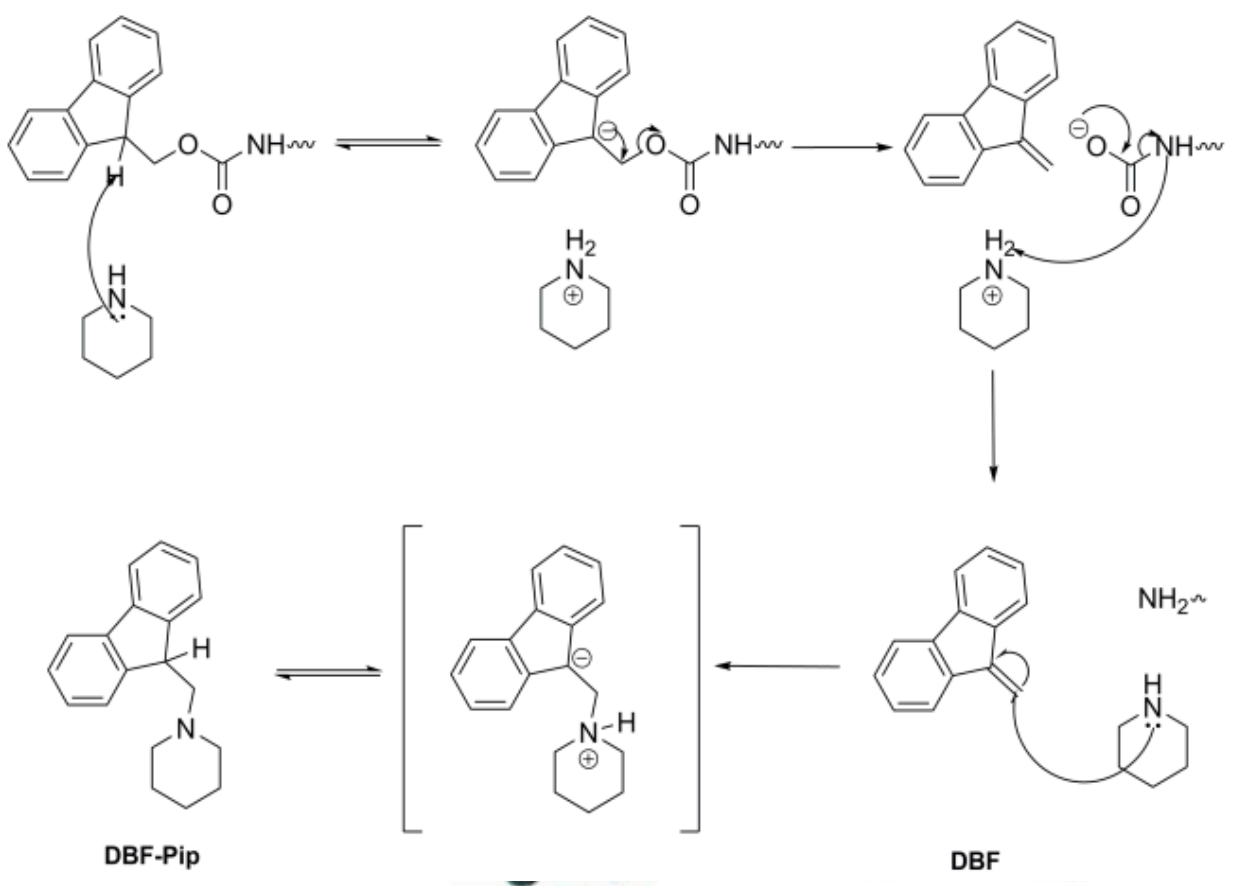

B

(i)

(ii)

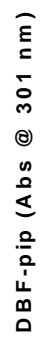

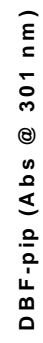

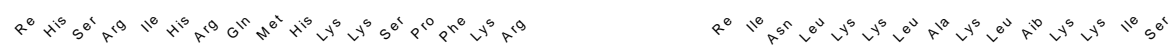




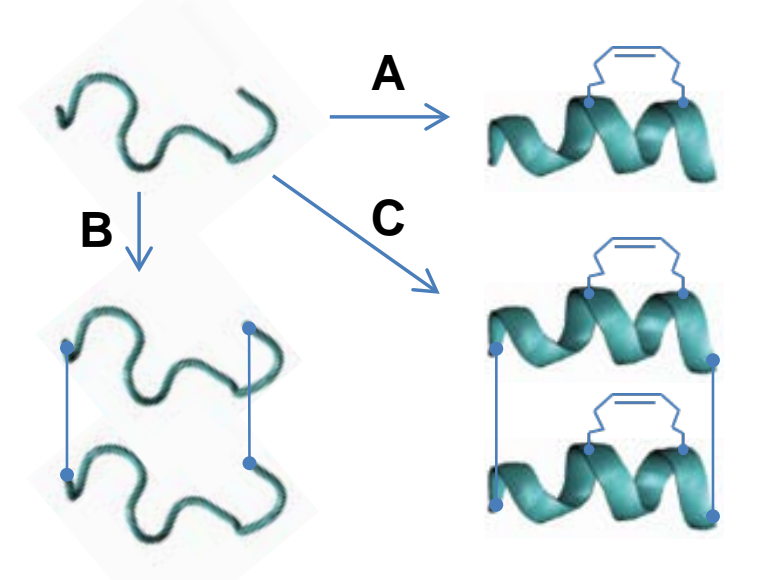

